\title{
Effects of Vitamin B6 on the Brain Glutamate Pyrovate Transaminase and Glutamate Oxaloacetate Transaminase in Young and Old Rats
}

\author{
Manoochehr Messripour ${ }^{1, *}$, Azadeh Mesripour $^{2}$ \\ ${ }^{1}$ Department of Clinical Biochemistry, Khorasgan Branch Islamic Azad University, Isfahan, Iran \\ ${ }^{2}$ Medical Plant Research Center, Shahre Kord University of Medical Sciences, Shahre Kord, Iran
}

\begin{abstract}
Excessive amounts of extracellular glutamate in brain are excitotoxic and lead to neuronal death. Glutamate pyrovate transamiase (GPT) and glutamate oxaloacetate transaminase (GOT) catalyze transamination of glutamate to alpha ketoglutarate. Because vitamin B6 is essential for the enzymes activities, this study was undertaken to examine the effect of vitamin $\mathrm{B} 6$ on age related changes of this enzyme in rat brain. Three and 30 months old male rats were injected with vitamin B6 and the animal's brains were homogenized in phosphate buffer and the enzymes activities were measured in the supernatant. The activities of the enzymes in aged rats were significantly lower as compared to that of young animals. Vitamin B6 induced activation of the brain enzymes in both ages, however, the activation was significantly pronounced in aged animals. Significant activation of GPT and GOT by vitamin B6 in aged rat brain may be resulted from either lower availability of vitamin B6 in aged animals, or lower affinity of the enzymes for pyridoxal 5-phosphate, which is likely to be related to conformational changes during aging. It is suggested that vitamin B6 may restore the activity of these enzymes during the brain aging.
\end{abstract}

Keywords Glutamate, Vitamin B6, Aging, GOT, GPT

\section{Introduction}

Numerous biochemical changes have been reported to occur in aging brain. A number of evidences are in favor of significant changes in several major neurotransmitters[1]. Glutamate is known as an excitatory amino acid neurotransmitter which interacts with N-methyl-D-aspartate (NMDA) receptors for basal excitatory synaptic transmission. Neurophysiological studies indicated that glutamate causes many forms of synaptic plasticity such as long-term ostentation and depression, which are thought to underlie learning and memory[2,3].On the other hand, excessive levels of extracellular glutamate in the nervous system are excitotoxic and lead to neuronal death and several neurodegenerative processes $(4,5,6)$. Several line of evidences suggested that increased extracellular glutamate, can give rise to many potentially damaging mechanisms which may be pathologically important [7-8]. Of particular interest are the beneficial therapeutic effects of glutamate receptor antagonists in Alzheimer's disease[2,3]. It is therefore proposed that rapid removal of the released glutamate in the synaptic

\footnotetext{
* Corresponding author:

m messripour@yahoo.com (Manoochehr Messripour)

Published online at http://journal.sapub.org/ajmms

Copyright (C) 2012 Scientific \& Academic Publishing. All Rights Reserved
}

cliff may also prevent the excessive excitation of glutamate receptors. Several enzymes are involved in removal of glutamate from synaptic regions; glutamine synthetase, which convert glutamate to glutamine, glutamate decarboxylase (GAD) that catalyses the synthesis of GABA, and aminotransferases which change glutamate to alpha- Ketoglutarate. Age related decreases in the expression and or activities of these enzymes in the brain have been very well established $(9,10)$. Recently we have reported that the activity of GAD in aged rats brain was $54 \%$ lower than that of young animals, which could be reactivated to the levels equivalent to young animals by administration of vitamin B6[11]. Because pyridoxal 5 '-phosphate acts as co-enzyme for aminotransferases as well, this study was extended to examine the effects of vitamin B6 administration on the brain glutamate pyrovate transaminase (GPT) and glutamate oxaloacetate transaminase (GOT)) in young and old rats.

\section{Materials and Methods}

Twenty four young ( 3 months old) male Wistar rats with weight ranging from 200 to $250 \mathrm{~g}$ and 24 old (30 months old) male Wistar rats (30 months old) with weight ranging from 650 to $720 \mathrm{~g}$ were used. Animals were maintained with respect to the animal welfare regulation in animal house until the desired age was attained. The animals were 
injected intraperitoneally with 1,10 and $100 \mathrm{mg}$ vitamin B6 $/ \mathrm{kg}$ body weight /day for a period of 30 days. Control group were injected with saline only. The control, and experimental groups were housed (6 rats in each group) in a regulated environment $\left(25 \pm 1{ }^{\circ} \mathrm{C} ; 50\right.$ to $55 \%$ relative humidity; $12 \mathrm{~h}$ light/dark cycle), with free access to food and water. The day after last injection the animals were killed by decapitation after anesthesia. The animal brains were removed immediately and homogenized in phosphate buffer $(\mathrm{pH} 7)$ at $4^{\circ} \mathrm{C}$ and centrifuged at $70,000 \mathrm{~g}$. The activity of GPT and GOT were measured in the supernatant by diagnostic kits (Chimienzyme Co, Tehran, Iran). Lowry's method was used for protein determination (12). Significance level was set at $\mathrm{p}<0.05$, using Student's t-test

\section{Results}

The specific activities of GPT and GOT in the brain of 3 and 30 month old rats are summarized in Table 1 . The activities of the enzymes in aged rats brain were 42 , and 28 percent lower that corresponding enzymes in the brain of young animals $(\mathrm{P}<0.05)$. The effects of vitamin $\mathrm{B} 6$ administration in doses of $0-100 \mathrm{mg} / \mathrm{Kg}$ body weight on the activity of the brain GPT and GOT of young and old rats are shown in the Figures 1 and 2. The enzymes were activated by administration of vitamin B6 in a linear fashion in both ages, although the activation was more pronounced in aged animals $(\mathrm{P}<0.05)$.

Table 1. Changes of GPT and GOT activities of in the brain of young and old rats

\begin{tabular}{|c|c|c|}
\hline Enzymes & 3 month old rats & 30 month old rats \\
\hline GPT & $22.4 \pm 4.6$ & $13.1 \pm 1.7^{*}$ \\
\hline GOT & $40.0 \pm 1.4$ & $28.8 \pm 1.7^{*}$ \\
\hline
\end{tabular}

Data are means \pm SD of 6 separate experiments, expressed as ng glutamate $/ \mathrm{min} / \mathrm{mg}$ protein.

*Differences are significant as compared to young animals $(\mathrm{P}<0.05)$.

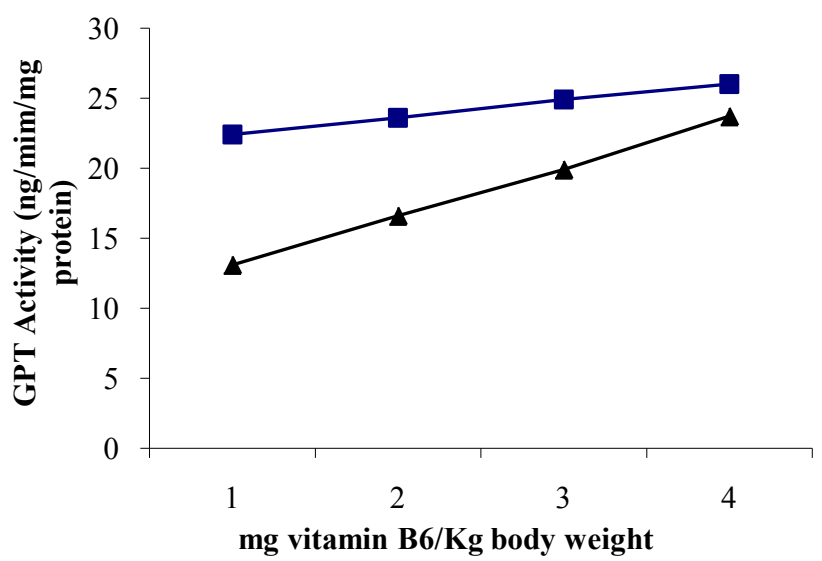

Figure 1. The effect of vitamin B6 on the activity of GPT in young and old rats

Each point is means of 6 separate experiments with SD less than $10 \%$, expressed as ng glutamate / $\mathrm{min} / \mathrm{mg}$ protein. 1, 2, 3 and 4 stand for; $0,1,10$ and $100 \mathrm{mg}$ vitamin B6/Kg body weight.
Each point is means of 6 separate experiments with SD less than $10 \%$, expressed as ng glutamate / $\mathrm{min} / \mathrm{mg}$ protein. $1,2,3$ and 4 stand for; $0,1,10$ and $100 \mathrm{mg}$ vitamin $\mathrm{B} 6 / \mathrm{Kg}$ body weight.

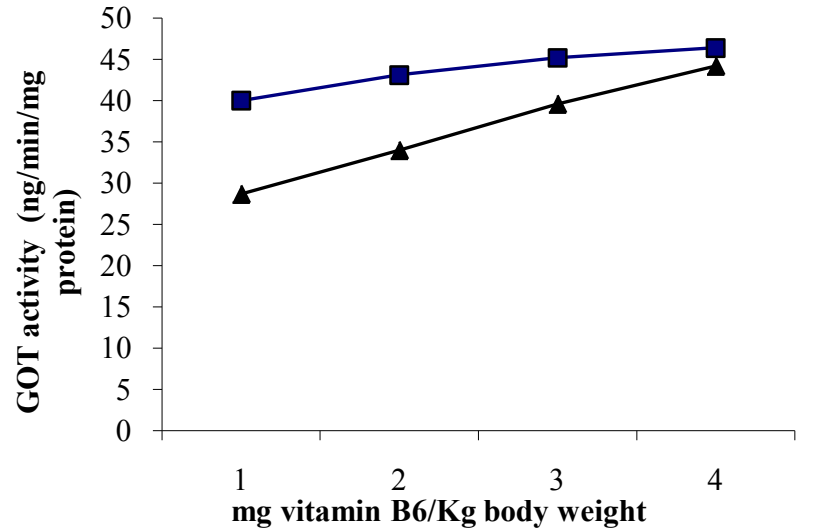

Figure 2. The effect of vitamin B6 on the activity of GOT in young and old rats

\section{Discussion}

The first part of this in vivo study sought to measure the specific activities of GPT and GOT in the brain as a function of the age of the rats The results indicate that the activities of these enzymes are significantly lower in the brain of aged rats as compare to those of young animals. Both GPT and GOT seem to be affected by aging. Apparently, lower rate of glutamate metabolism in aging brain leads to its accumulation and selective toxicity in glutmitergic terminals. This suggestion is interpreted as being consisted with the hyperactivity of glutamatergic system in aged brain[13,14].

Activation of GPT and GOT by vitamin B6 indicates that pyridoxal 5-phosphate is an essential part of the active site of the enzymes for the amino acid substrates. Because vitmine B6 activate the enzyme activities in both ages, it appears that pyridoxal 5-phosphate in the active site of these enzymes is at suboptimal levels. However, the rate of activation of the enzymes in the brain of aged rats was considerably greater than in young animals. Although provided data is not adequate to suggest about the interaction of prydoxal 5-phosphate with these enzymes at the molecular levels, it seems that $t$ significant activation of the enzymes in aged rat brain with high levels of vitamin B6, might be resulted from either; lower availability of vitamin B6 in aged animals, or; lower affinity of the enzymes for pyridoxal 5phosphate. The latter is likely to be related to the posttranslational modifications of the proteins as consequences of aging[1]. This is consistent with the results reported from the treatment of individuals with mild to moderate cognitive disorders with B vitamin supplements[15]. Although, glutamate metabolizing enzymes might be considered as a therapeutic target for prevention of neurodegenerative disorders and age related symptoms, it seems unlikely to improve Alzheimer's disease symptoms. It is however, concluded that restoring the activity of these enzymes in aged 
animals by vitamin B6 to the levels equivalent to young animals might prevent the glutamate neurotoxicity during aging. This is in good agreement with the experimental study of Campos et al.[16], how showed neuroprotective effect of GOT in ischemic stroke. However, further research is necessary to determine whether or not the health benefit of increased vitamin B6 intake would improve or reduce the incidences of some of the diseases which commonly occur with aging.

\section{REFERENCES}

[1] Messripour, M., Weltin, D., Rastegar, A., Ciesielski, L., Kopp, P., Chabert, M., Mandel, P., 1994, Age-associated changes of rat brain neuronal and astroglial poly (ADP-ribose) polymerase activity. J. Neurochem. 62(2):502-6

[2] Hardy, J., Adolfsson, R., Alafuzoff, I., Bucht, G., Marcusson, J., Nyberg, P., 1985, Transmitter deficits in Alzheimer's disease. Neurochem Int. 7:545-63

[3] Reinikainen, KJ., Paljarvi, L., Huuskonen, M., Soininen, H., Laakso, M., Riekkinen, PJ.. 1988 A post-mortem study of noradrenergic, serotonergic and GABAergic neurons in Alzheimer's disease. J Neurol Sci; 84:101-16.

[4] Kvamme, E., 1998, Synthesis of glutamate and its regulation, Prog Brain Res. 116:73-85

[5] Daniel, JB., Daniel, EF., 2008, Synapse-specific expression of functional presynaptic NMDA receptors in rat somatosensory cortex. J Neurosci;27;28(9):2199-2211

[6] Corlew, R., Brasier, DJ., Feldman, DE., Philpot, BD.. 2008 Presynaptic NMDA receptors: newly appreciated roles in cortical synaptic function and plasticity. Neuroscientist; 14(6):609-25

[7] Hoop, B., Masjedi, MR., Shih, VE.. Kazemi, H., 1990, Brain glutamate metabolism during hypoxia and peripheral chemodenervation. J. Appl. Physiol. 69, 147-154
[8] Thomas, RJ., 1995, Excitatory amino acids in health and disease. J.Am. Geriatrics Soc., 43(11): 1279-1289

[9] Olabarria, M., Noristani, HN., Verkhratsky, A., Rodríguez, JJ., 2011, Age-dependent decrease in glutamine synthetase expression in the hippocampal astroglia of the triple transgenic Alzheimer's disease mouse model: mechanism for deficient glutamatergic transmission? Mol Neurodegener. 30; $6: 55$

[10] Rajeswari, TS., Radha, E., 1984, Metabolism of the glutamate group of amino acids in rat brain as a function of age, Mechanisms of Ageing and Development,24, (2), 139-149

[11] Messripour, M. Mesripour, A., 2011, Effects of vitamin B6 on age associated changes of ratbrain glutamate decarboxylase activity,African Journal of Pharmacy and Pharmacology , $5(3), 454-456$

[12] Lowry, OH., Rosebrough, NJ., Farr, AL., Randall, RJ., 1951, Protein measurement with the folin phenol reagent . J. Biol. Chem.193, 265- 275

[13] Sarah, L., Milton, J., Thompson, W., Lutz, PL., 2002, Mechanisms for maintaining extracellular glutamate levels in the anoxic turtle striatum. Am J Physiol Regul Integr Comp Physiol., 282: R1317-R1323

[14] Shevtsov, PN., Shevtsova, EF., Burbaeva, GS., 2008, Effect of tacrine, amiridine, akatinol memantine, and triazolam on phosphorylation, structure, and assembly of microtubules from brain microtubular proteins in Alzheimer diseases. Bull Exp Biol Med. 145(2):218-222

[15] Sun, Y., Lu, CJ., Chien, KL., 2007. Efficacy of multivitamin supplementation containing vitamins B6 and B12 and folic acid as adjunctive treatment with a cholinesterase inhibitor in Alzheimer's disease: a 26-week, randomized, double-blind, placebo-controlled study in Taiwanese patients. Clin. Clin. Ther., 29(10): 2204-2214

[16] Campos, F., Sobrino, T., Ramos-Cabrer , P., Argibay, B., Agulla, J., Pérez-Mato, M., Rodríguez-González, R., Brea, D., Castillo, J., 2011, Neuroprotection by glutamate oxaloacetate transaminase in ischemic stroke: an experimental study, J Cereb Blood Flow Metab. 31(6):1378-86 